\title{
Relationship between inclusion level of Vachellia tortilis leaf meal and behavioral activities of finishing pigs
}

\author{
Fortune Thabethe', Mbongeni Khanyile ${ }^{1}$, Cyprial Ndumiso Ncobela ${ }^{2}$, and Michael Chimonyo ${ }^{1, *}$
}

* Corresponding Author: Michael Chimonyo Tel: +27-33-260 5477, Fax: +27-33-260-5067,

E-mail: chimonyo@ukzn.ac.za

${ }^{1}$ Animal and Poultry Science, University of KwaZuluNatal, P. Bag X01 Scottsville 3209, Pietermaritzburg, South Africa

${ }^{2}$ Department of Agriculture, Faculty of Science and Agriculture, University of Zululand, KwaDlangezwa 3886, South Africa

\section{ORCID}

Fortune Thabethe

https://orcid.org/0000-0002-4604-1364 Mbongeni Khanyile

https://orcid.org/0000-0002-1749-6730

Cyprial Ndumiso Ncobela

https://orcid.org/0000-0002-9190-3250

Michael Chimonyo

https://orcid.org/0000-0002-3244-0444

Submitted Nov 23, 2018; Revised Dec 26, 2018; Accepted Jan 28, 2019
Objective: The study was conducted to establish a relationship between inclusion level of Vachellia tortilis ( $V$. tortilis) leaf meal and time spent on different behavioral activities by finishing pigs.

Methods: A total of forty-eight male Large White $\times$ Landrace finishing pigs with a mean ( \pm standard deviation) body weight of $63.8 \pm 3.28 \mathrm{~kg}$ aged $14 \mathrm{wks}$ were assigned to individual pens in a completely randomized design. Pigs were fed on diets containing $0,30,60,90,120$, and $150 \mathrm{~g} / \mathrm{kg}$ dry matter of $V$. tortilis leaf meal ad libitum with fresh water provided throughout the trial. There were eight pigs in each experimental diet. The behavior of pigs was observed for three wks twice a wk from 0600 to $1800 \mathrm{~h}$ using six closed circuit television cameras.

Results: Increasing levels of $V$. tortilis leaf meal caused a linear decrease $(\mathrm{p}<0.05)$ in time spent eating, lying down and the number of visit to the feeder. Time spent standing and biting objects increased linearly $(\mathrm{p}<0.05)$ with increasing inclusion level of $V$. tortilis leaf meal. The was a negative linear relationship $(\mathrm{p}<0.05)$ between condensed tannins versus time spent eating, lying down and number of feeder visits. Condensed tannins showed a positive linear relationship $(\mathrm{p}<0.05)$ with time spent standing and biting objects. Neutral detergent fiber caused a linear decrease $(p<0.05)$ in number of feeder visits, time spent eating, time spent standing.

Conclusion: Inclusion level of $V$. tortilis leaf meal reduces time spent eating, lying down and the number of feeder visit while prolonging time spent standing and biting of objects. Condensed tannins and dietary fiber are among nutritional factors affecting behavioral activities displayed by finishing pigs.

Keywords: Fiber; Proanthocyanidins; Relationship; Time Spent

\section{INTRODUCTION}

In tropical regions, there is a growing trend towards the use of leaves from leguminous trees as protein source in pig diets [1]. This is propelled by climate change and poor vegetation management practices, which increases the dominance of shrub legumes compared to grasses in rangelands [2]. The use of leguminous leaves is also stimulated by escalating prices of protein-rich conventional feedstuffs such as soybean due to competition with human. Leguminous trees such as Vachellia tortilis ( $V$. tortilis) are abundantly available, accessible and have reasonable nutrient profile $[1,2]$. $V$. tortilis has high levels of crude protein that ranges from 160 to $218 \mathrm{~g} / \mathrm{kg}$ dry matter (DM) [3], which makes it appropriate to be used as a source of amino acids. It is also rich in neutral detergent fiber (NDF, 324 to $373 \mathrm{~g} / \mathrm{kg} \mathrm{DM}$ ), acid detergent fiber (ADF, 138 to $171 \mathrm{~g} / \mathrm{kg} \mathrm{DM}$ ) and polyphenols such as condensed tannins (2.61 to $12.9 \mathrm{mg} / \mathrm{kg} \mathrm{DM}$ ) [1]. Except growth performance [4], welfare aspect of using $V$. tortilis in finishing is often ignored yet it helps to broadly understand the worth of utilizing this feedstuff in pigs. 
There is a compelling evidence that finishing pigs fed fibrous diet spend more time ingesting their daily diet and displaying stronger mastication movements $[5,6]$. The amount of condensed tannins (also known as proanthocyanidins) and fiber present in Vachellia leaf meals may also influence behavioral activities of finishing pigs $[4,6]$. V. tortilis contains proanthocynadins, which are plant-derived flavonoid polymers, bind with and engulf protein [7] thus compromising protein availability, digestibility and utilisation and this may have an indirect bearing on behavior of pigs [4]. To maximize the utilization of $V$. tortilis as feedstuff for pigs, information on the relationship between $V$. tortilis leaf meal against condensed tannins coupled with fiber is indispensable. Very few, if any, studies conducted to investigate the relationship between $V$. tortilis against behavioral activities. High inclusion of $V$. tortilis causes an astringent taste $[1,8]$, thereby compromises growth performance, prolonging adaptation to the diet [4] and may influence feeding and stereotypic behavior in pigs. The current study helps in providing information about the homeostatic and welfare status of finishing pigs fed varying levels of $V$. tortilis. It also helps to gauge optimum inclusion levels of $V$. tortilis without undermining behavioral activities. It was hypothesized that $V$. tortilis leaf meal inclusion has no relationship with time spent on behavioral activities of pigs. The objective of the study was to determine the relationship between incremental levels of $V$. tortilis leaf meal and time spent on behavioral activities of finishing pigs.

\section{MATERIALS AND METHODS}

\section{Description of study site and collection of Vachellia tortilis leaves}

The study was conducted at Ukulinga Research Farm, University of KwaZulu-Natal (UKZN), Pietermaritzburg, South Africa. The farm is positioned $29^{\circ} 24^{\prime} \mathrm{E}$ and $30^{\circ} 24^{\prime} \mathrm{S}$ having an altitude of $775 \mathrm{~m}$ above sea level. The daytime mean temperatures ranges from $28^{\circ} \mathrm{C}$ to $43^{\circ} \mathrm{C}$. The vegetation at the farm consists of several types of trees and grass species which include Vachellia species. The average rainfall is $735 \mathrm{~mm}$. V. tortilis leaves were hand harvested at Makhathini Research Station, Jozini, South Africa. The leaves were harvested between April and May 2016 during post rainy season at an advanced stage of maturity according to the method described by Khanyile et al [1]. Briefly, leaves were harvested green, airdried under shade by spreading on polyethylene sheets at room temperature for $72 \mathrm{~h}$.

\section{Ethical consideration}

The care and use of pigs were done according to the ethical guidelines stated by the certification of authorization to experiment on living animals given by the UKZN animal ethics committee: (Reference Number: AREC/101/015D).

\section{Pigs and housing management}

A total of 48 clinically healthy male F1 hybrid (Large Whitex Landrace) pigs of 14 wks of age, were used in the study. The mean ( \pm standard deviation) body weight of the pigs was 63.8 $\pm 3.28 \mathrm{~kg}$. The pigs were obtained from Kanhym farm in KwaZulu-Natal, South Africa, where they were housed in groups, to Ukulinga Research Farm (UKZN), where they were housed in individual pens. Prior to arrival, the pig house was disinfected with a natural disinfectant. A footbath was placed at the entrance of the pig house for biosecurity measures. The pigs were reared on individual pens having barren slatted floors measuring $2.1 \times 1.1 \mathrm{~m}^{2}$. There was no any form of environmental enrichment in the pens and surroundings that would disturb behavior of pigs during the experiment. The pig barn had five rows of 16 pens. Of these, 3 rows of 16 pens were used to individually house pigs. Pigs were able to see each other across the row and next to each other. Prior to the diet treatment, pigs were all fed commercial diet without $V$. tortilis. Artificial lights were automatically switched on and off from $1800 \mathrm{~h}$ and $800 \mathrm{~h}$, respectively. The house had raising curtains on both sides that were opened at $0845 \mathrm{~h}$ and closed at $1630 \mathrm{~h}$. All pigs had free access to clean fresh water which was provided through low pressure nipple drinkers. They also had ad libitum access to feed which was offered through preweighed plastic self-feeder troughs (Big Dutchman Lean Machine, Postfach, Vechta, Germany).

\section{Experimental design and diets}

Eight pigs were allocated using a completely randomized design into each of the six experimental diets. Each pig was used an experimental unit. Pigs had already adapted to the diet. The adaptation consisted of $10 \mathrm{~d}$ of adaptation experiment and $21 \mathrm{~d}$ of growth performance experiment [4]. The inclusion levels tested were $0,30,60,90,120$, and $150 \mathrm{~g} / \mathrm{kg}$ DM of $V$. tortilis leaf meal. Maximum inclusion level of leaf meal was determined by the digestibility estimates of energy and amino acids [1]. The diets were formulated to be isoproteinic and isocaloric using Winfeed (Winfeed Limited, Cambridge, UK) feed formulation software. Vitamins and mineral were supplemented to meet NRC recommended specification for finishing pigs [9]. Pigs were not supplemented with growth promoters. Table 1 is showing the ingredient composition of experimental diets. Average daily feed intakes of finishing pigs fed on $0,30,60,90,120,150 \mathrm{~g} / \mathrm{kg}$ DM of inclusion level of $V$. tortilis were 2.97, 2.96, 3.08, 2.82, 2.73 and $2.76 \mathrm{~kg} / \mathrm{d}$, respectively [4]. The average daily gain was $1.01,101,103,0.96,0.91$, and $1.02 \mathrm{~kg} / \mathrm{d}$, respectively.

\section{Chemical composition of diets}

Before analyzing the experimental diets, samples from each diet were ground through a $2 \mathrm{~mm}$ sieve at Ukulinga Research Farm, Pietermaritzburg. After milling, the samples were 
Table 1. Ingredient composition of experimental diets (g/kg DM)

\begin{tabular}{|c|c|c|c|c|c|c|}
\hline \multirow{2}{*}{ Ingredient (g/kg) } & \multicolumn{6}{|c|}{ Vachellia tortilis inclusion level (g/kg DM) } \\
\hline & 0 & 30 & 60 & 90 & 120 & 150 \\
\hline Maize & 458 & 432 & 406 & 382 & 357 & 333 \\
\hline Wheat bran & 356 & 346 & 337 & 326 & 315 & 304 \\
\hline Soybean 46 & 86 & 91.2 & 94.4 & 101 & 106 & 111 \\
\hline Vachellia tortilis leaves & 0 & 30 & 60 & 90 & 120 & 150 \\
\hline Oil-sunflower & 60.1 & 61.1 & 62.0 & 62.9 & 63.8 & 64.8 \\
\hline Limestone & 20.9 & 20.4 & 19.9 & 19.5 & 18.9 & 18.2 \\
\hline Monocalcium phosphate & 9.61 & 9.9 & 10.2 & 10.5 & 10.8 & 11.1 \\
\hline Salt & 4.9 & 5.0 & 5.02 & 5.03 & 5.03 & 5.05 \\
\hline Vitamin-mineral premix ${ }^{1)}$ & 1.5 & 1.5 & 1.5 & 1.5 & 1.5 & 1.5 \\
\hline L-lysine-HCL & 1.64 & 1.44 & 1.24 & 1.05 & 0.85 & 0.65 \\
\hline Threonine & 0.97 & 0.86 & 0.75 & 0.64 & 0.52 & 0.4 \\
\hline Methionine & 0.38 & 0.42 & 0.46 & 0.5 & 0.54 & 0.58 \\
\hline
\end{tabular}

DM, dry matter.

1) Provides (/kg of DM of diet): vitamin $A, 4.8 \mathrm{mg}$; vitamin $D_{3}, 0.09 \mathrm{mg}$; vitamin $E_{1} 50 \mathrm{mg}$; vitamin $K_{3}(43 \%), 1.0 \mathrm{mg}$; vitamin $B_{1}, 1.6 \mathrm{mg}$; vitamin $B_{2}, 2.6 \mathrm{mg} ;$ niacin $(99.5 \%)$, $33.6 \mathrm{mg}$; vitamin $B_{12}, 0.01 \mathrm{mg}$; vitamin $B_{6} 98 \%, 2.0 \mathrm{mg}$; choline (chloride $\left.60 \%\right), 121 \mathrm{mg}$; folic acid ( $96 \%$ pure), $0.48 \mathrm{mg}$; biotin, $0.18 \mathrm{mg}$; calcium pantothenate ( $98 \%$ ), $5.2 \mathrm{mg}$; zinc balitracin, $90.0 \mathrm{mg}$; manganese sulphate, $120.0 \mathrm{mg}$; zinc, $100 \mathrm{mg}$; copper, 8 mg; potassium iodide (lodine $76.45 \%$ ), $0.4 \mathrm{mg}$; cobalt sulphate, $0.2 \mathrm{mg}$; ferrous sulphate, $100.0 \mathrm{mg}$; and selenium, $0.32 \mathrm{mg}$ on dolomite carrier.

analyzed in triplicate, at the Animal and Poultry Science Laboratory at UKZN, Pietermaritzburg. Briefly, DM content was determined by the oven drying method, samples were dried for $4 \mathrm{~d}$ at $65^{\circ} \mathrm{C}$. Dry samples were incinerated at $550^{\circ} \mathrm{C}$ overnight for ash content determination according to method 990.05 [10]. The dried samples were subjected to bomb calorimetry to determine gross energy. Ether extract was determined using the Soxhlet apparatus following method 920.39 described by AOAC [10]. Crude protein content was calculated using the formula: $\mathrm{N} \times 6.25$, were nitrogen content was determined following the Dumas Combustion method in a Leco Truspec Nitrogen Analyser, St. Joseph, MI, USA by method 990.3 of AOAC [10]. The NDF and ADF were determined using the Ankom Fiber Analyzer (Ankom Macedon, NY, USA) according to [11]. The NDF was analysed using heat stable $\alpha$-amylase (sigma A3306; Sigma Chemical Co., St. Louis, MO, USA).

The water holding capacity (WHC) was determined following methods described by Whittemore et al [12]. Briefly, $0.5 \mathrm{~g}$ of each feed sample was placed into a $50 \mathrm{~mL}$ centrifuge machine and distilled water of $25 \mathrm{~mL}$ was added. The tubes were wrapped and shake for $24 \mathrm{~h}$ and centrifuged at $6,000 \times \mathrm{g}$ for $15 \mathrm{~min}$ at $20^{\circ} \mathrm{C}$. The formed supernatant was discarded and the new weight of the sample was recorded. After freezedrying, the weights of the recollected fluids were calculated from the difference between the new sample and the dried sample. The weight of the recollected fluid was divided by the weight of the dried sample to determine the WHC of the feed sample, which was then expressed in $g$ water/g of dry material. Bulk density was determined using the water displacement method as described by Kyriazakis and Emmans
[13]. For mineral analyses, ground samples were ashed at $550^{\circ} \mathrm{C}$ overnight and dissolved in a 1 M HCL [14], then analysed using the Varian 720 Inductively Coupled Plasma Emision Spectrometer (ICP- OES, Frankfurt, Germany) with an atomic absorption. Proanthocyanidins content was detected calorimetrically by the butanol-HCL process described by Reed et al [15]. For amino acids, acid hydrolysis was used according to method 982.30 described by AOAC [10]. Before analyses via amino acid analyser (SY-KAM, Erising, Gewerbering, Germany), modifications were made as explained by Mills et al [16]. The chemical composition of the diets is given in Table 2.

\section{Measuring behavioral activities}

Behavioral activities were observed on individual pigs for three wks, twice a wk from $0800 \mathrm{am}$ to $1800 \mathrm{~h}$, using six motorized indoor closed circuit television cameras. Cameras were installed in different locations in the housing pen such that each camera appropriately captured eight pigs. All cameras were attached to a digital video recorder control system and transcend one terabyte external hard drive. The use of video cameras was adopted to avoid disturbances during behavioral data collection. Behavioral activities recorded were time spent eating, drinking, standing, lying down, sniffing, biting, licking objects and the number of visits to the feeder. The description of behavioral activities is given in Table 3. As described by Bakare et al [6], time spent on each behavioral activity was divided by body weight of a pig. This was done to account for variation that could be caused by body weight when measuring behavioral activities. 
Table 2. Nutrient composition of experimental diets

\begin{tabular}{|c|c|c|c|c|c|c|}
\hline \multirow{2}{*}{ Component } & \multicolumn{6}{|c|}{ Vachellia tortilis inclusion level (g/kg DM) } \\
\hline & 0 & 30 & 60 & 90 & 120 & 150 \\
\hline $\mathrm{DM}(\mathrm{g} / \mathrm{kg})$ & 946 & 935 & 899 & 940 & 897 & 896 \\
\hline $\mathrm{GE}(\mathrm{MJ} / \mathrm{kg})$ & 17.6 & 17.5 & 17.3 & 17.3 & 17.4 & 17.2 \\
\hline Ash (g/kg DM) & 90 & 90 & 90 & 89 & 89 & 86 \\
\hline$C P(g / k g D M)$ & 144 & 140 & 142 & 146 & 146 & 148 \\
\hline $\mathrm{EE}(\mathrm{g} / \mathrm{kg} \mathrm{DM})$ & 114 & 104 & 109 & 114 & 113 & 116 \\
\hline Starch (g/kg DM) & 318 & 321 & 305 & 274 & 239 & 225 \\
\hline ADF (g/kg DM) & 137 & 136 & 139 & 145 & 145 & 147 \\
\hline NDF (g/kg DM) & 303 & 313 & 321 & 339 & 348 & 356 \\
\hline Lysine (g/100g DM) & 10.3 & 10.1 & 10.1 & 10.5 & 11.0 & 10.7 \\
\hline Threonine (g/100g DM) & 7.2 & 7.2 & 7.5 & 8.0 & 7.5 & 8.0 \\
\hline Methionine (g/100g DM) & 5.0 & 4.3 & 4.5 & 4.3 & 4.8 & 5.0 \\
\hline $\mathrm{CT}$ (mg/kg DM) & - & 2.3 & 3.1 & 5.1 & 6.6 & 7.9 \\
\hline $\mathrm{BD}(\mathrm{mL} / \mathrm{g} \mathrm{DM})$ & 1.31 & 1.52 & 1.59 & 1.63 & 1.64 & 1.69 \\
\hline WHC $\left(g_{\text {water }} / g_{\text {feed }} D M\right)$ & 2.27 & 2.4 & 2.61 & 2.88 & 3.23 & 3.44 \\
\hline Calcium (g/kg DM) & 10.1 & 15.4 & 16.8 & 17.3 & 17.2 & 19.8 \\
\hline Phosphorus (g/kg DM) & 7.3 & 9.7 & 10.1 & 10.7 & 10.3 & 11.9 \\
\hline Magnesium (g/kg) & 9.8 & 8.9 & 10.1 & 10.1 & 9.3 & 10.1 \\
\hline Potassium (g/kg) & 8.8 & 9.0 & 9.3 & 10.2 & 10.4 & 11.1 \\
\hline Sodium (g/kg) & 2.3 & 5.3 & 10.2 & 10.1 & 9.8 & 12.3 \\
\hline Zinc $(\mathrm{mg} / \mathrm{kg})$ & 90.8 & 91.1 & 88.3 & 81.2 & 82.3 & 78.2 \\
\hline Copper (mg/kg) & 8.9 & 7.8 & 9.14 & 8.15 & 7.23 & 7.31 \\
\hline Manganese (mg/kg) & 124 & 111 & 109 & 124 & 123 & 128 \\
\hline Iron (mg/kg) & 146 & 201 & 304 & 338 & 344 & 359 \\
\hline
\end{tabular}

DM, dry matter; GE, gross energy; CP, crude protein; EE, ether extract; ADF, acid detergent fiber; NDF, neutral detergent fiber; $C T$, condensed tannins; BD, bulk density; WHC, water holding capacity.

\section{Statistical analyses}

The PROC UNIVARIATE procedure of SAS [17] was used to determine the normality of the data for time spent on each behavioral activity (eating, feeder visit, drinking, lying down, standing, sniffing, object biting, and licking). Then data for time spent on each behavioral activity were normalized using logarithmic transformation since it was not normally distributed. The PROC CORR procedure of SAS [17] was used to determine the correlation between each behavioral activity and the chemical components $V$. tortilis leaf meal inclusion.

Table 3. Ethogram of recorded behavioral activities

\begin{tabular}{|c|c|}
\hline Behavior & Description of behavior \\
\hline Eating & $\begin{array}{l}\text { Feed consumption from the feeder / snout in contact with the } \\
\text { feeder }\end{array}$ \\
\hline Drinking & $\begin{array}{l}\text { Manipulating the nipple / snout in contact with the nipple } \\
\text { drinker }\end{array}$ \\
\hline Feeder visit & When a pig goes to the feeder \\
\hline Standing & Body supported by four legs without stamping \\
\hline Lying down & Lying ventral or lateral with sternum in contact with the floor \\
\hline Sniffing & When sniffing is performed against the pen floor \\
\hline Biting & $\begin{array}{l}\text { When biting is performed against the pen objects } \\
\text { (chain and sides of the pen) }\end{array}$ \\
\hline Licking & When licking is performed against the pen objects \\
\hline
\end{tabular}

The PROC RSREG procedure of SAS [17] was used to determine relationship between inclusion levels of $V$. tortilis leaf meal against time spent on each behavioral activity. The regression analysis was also used to relate behavioral activities and chemical components of $V$. tortilis leaf meal.

The regression model used was: $Y=\beta_{0}+\beta_{1} V+\beta_{2} V^{2}+E$

Where: $\mathrm{Y}$ is the response variables (time spent eating, drinking, lying down, standing, sniffing, object biting and licking and the number of feeder visits); $\beta_{0}, \beta_{1}, \beta_{2}$ regression coefficients; $\mathrm{V}$ is the inclusion level of $V$. tortilis leaf meal; $\mathrm{E}$ is the residual error.

\section{RESULTS}

\section{Correlation coefficients between behavioral activities of pigs and chemical components of the feeds}

The correlation coefficients among each behavioral activity are shown in Table 4 . Time spent eating was positively correlated $(\mathrm{p}<0.05)$ to the number of visits to the feeders. A negative correlation $(\mathrm{p}<0.05)$ was observed between the number of feeder visits and time spent standing and sniffing walls in the pens. Time spent standing was positively correlated $(\mathrm{p}<0.05)$ with 
Table 4. Pearson's correlation coefficients among behavioral activities of finishing pigs fed Vachellia tortilis leaf meal

\begin{tabular}{|c|c|c|c|c|c|c|c|c|}
\hline Items & ET & DK & FV & ST & LY & SN & OB & $\mathrm{OL}$ \\
\hline ET & - & $1.18^{\mathrm{NS}}$ & $0.24^{*}$ & $0.08^{\mathrm{NS}}$ & $-0.02^{\mathrm{NS}}$ & $0.09^{\mathrm{NS}}$ & $-0.04^{\mathrm{NS}}$ & $-0.00^{\mathrm{NS}}$ \\
\hline DK & - & - & $0.37^{* *}$ & $0.03^{\mathrm{NS}}$ & $0.84^{\mathrm{NS}}$ & $0.32^{\mathrm{NS}}$ & $0.27^{\mathrm{NS}}$ & $0.10^{\mathrm{NS}}$ \\
\hline $\mathrm{FV}$ & - & - & - & $-0.21^{*}$ & $0.09^{\mathrm{NS}}$ & $-0.23^{*}$ & $0.11^{\mathrm{NS}}$ & $-0.01^{\mathrm{NS}}$ \\
\hline ST & - & - & - & - & $-0.07^{\mathrm{NS}}$ & $0.47^{* *}$ & $0.62^{* *}$ & $0.43^{* *}$ \\
\hline LY & - & - & - & - & - & $0.02^{\mathrm{NS}}$ & $0.01^{\mathrm{NS}}$ & $-0.12^{\mathrm{NS}}$ \\
\hline SN & - & - & - & - & - & - & $0.29^{*}$ & $0.01^{\mathrm{NS}}$ \\
\hline$O B$ & - & - & - & - & - & - & - & $0.36^{*}$ \\
\hline $\mathrm{OL}$ & - & - & - & - & - & - & - & - \\
\hline
\end{tabular}

$E T$, time spent eating; DK, time spent drinking; FV, number of feeder visit; ST, time spent standing; LY, time spent lying down; SN, time spent sniffing; OB, time spent biting objects; OL, time spent licking objects.

Significance level: ${ }^{* *} p<0.001 ;{ }^{* *} p<0.01 ;{ }^{*} p<0.05 ;$ NS, not significant $(p>0.05)$.

time spent sniffing the walls, biting and licking of objects. Time spent lying down was not correlated to any behavioral pattern. Time spent sniffing the walls was positively correlated $(\mathrm{p}<0.05)$ to time spent biting objects. A positive correlation $(\mathrm{p}<0.05)$ was observed between time spent biting and licking objects. The number of feeder visits were positively correlated $(\mathrm{p}<0.05)$ with time spent standing, sniffing the walls and biting objects. Table 5 shows the correlation coefficients of condensed tannins and fiber of $V$. tortilis leaf meal against behavioral activities. There was a negative correlation $(\mathrm{p}<0.05)$ between $\mathrm{ADF}$ content and time spent standing, sniffing walls and biting objects. The NDF showed a negative correlation $(\mathrm{p}<0.05)$ with time spent eating. Condensed tannins were positively correlated $(\mathrm{p}<0.001)$ with time spent sniffing walls, biting and licking objects and negatively correlated with time spent eat- ing, drinking, number of feeder visits $(\mathrm{p}<0.001)$, standing and lying down $(\mathrm{p}<0.05)$.

\section{Relationship between increasing level of Vachellia tortilis leaf meal and time spent on behavioral activities of pigs}

Table 6 shows the relationship on time spent on behavioral activities with increasing levels of $V$. tortilis leaf meal. A linear decrease $(\mathrm{p}<0.05)$ in time spent time eating and lying down was observed with increasing level of $V$. tortilis leaf meal. The time spent standing and biting objects increased linearly with increasing level of $V$. tortilis leaf meal $(\mathrm{p}<0.05)$. There was no relationship in time spent on drinking, sniffing walls and licking of objects with increasing level of $V$. tortilis leaf meal. The regression equations of behavioral activities are shown in Table

Table 5. Pearson's correlation coefficients of behavioral activities of finishing pigs against condensed tannins and fiber of Vachellia tortilis leaf meal

\begin{tabular}{|c|c|c|c|c|c|c|c|c|}
\hline Components & ET & DK & FV & ST & $\mathrm{LY}$ & SN & OB & $\mathrm{OL}$ \\
\hline Acid detergent fiber (g/kg DM) & $0.18^{\mathrm{NS}}$ & $-0.16^{\mathrm{NS}}$ & $0.09^{\mathrm{NS}}$ & $-0.27^{*}$ & $0.16^{\mathrm{NS}}$ & $-0.28^{*}$ & $-0.30^{*}$ & $0.33^{\mathrm{N}}$ \\
\hline Neutral detergent fiber ( $\mathrm{g} / \mathrm{kg} \mathrm{DM}$ ) & $-0.29^{*}$ & $0.19^{\mathrm{NS}}$ & $-0.21^{*}$ & $0.26^{*}$ & $-0.13^{\mathrm{NS}}$ & $0.28^{*}$ & $0.35^{*}$ & $0.35^{\mathrm{N}}$ \\
\hline Condensed tannins (mg/kg DM) & $-0.50 * *$ & -0.44 & $-0.47^{* *}$ & $0.37^{*}$ & $-0.45^{\mathrm{NS}}$ & $0.49^{* *}$ & $0.38^{*}$ & $0.42^{*}$ \\
\hline
\end{tabular}

DM, dry matter; ET, time spent eating; DK, time spent drinking; FV, number of feeder visit; ST, time spent standing; LY, time spent lying down; SN, time spent sniffing; OB, time spent biting objects; OL, time spent licking objects.

Significance level ${ }^{* *} p<0.001 ;{ }^{* *} p<0.01 ;{ }^{*} p<0.05$; NS not significant $(p>0.05)$.

Table 6. Relationship between time spent on behavioral activities with increasing level of Vachellia tortilis leaf meal

\begin{tabular}{|c|c|c|c|c|c|c|c|c|c|}
\hline \multirow{2}{*}{ Activity (min/d/BW) } & \multicolumn{6}{|c|}{ Vachellia tortilis inclusion level (g/kg DM) } & \multirow{2}{*}{ SEM } & \multicolumn{2}{|c|}{ Polynomial regression } \\
\hline & 0 & 30 & 60 & 90 & 120 & 150 & & Linear & Quadratic \\
\hline ET & 2.31 & 2.22 & 2.21 & 2.21 & 2.21 & 2.17 & 0.01 & * & NS \\
\hline DK & 1.64 & 1.58 & 1.53 & 1.67 & 1.66 & 1.58 & 0.02 & NS & NS \\
\hline ST & 1.31 & 1.25 & 1.37 & 1.38 & 1.71 & 1.39 & 0.01 & * & NS \\
\hline LY & 2.47 & 2.47 & 2.41 & 2.37 & 2.34 & 2.44 & 0.03 & * & NS \\
\hline SN & 1.42 & 1.52 & 1.48 & 1.52 & 1.62 & 1.57 & 0.06 & NS & NS \\
\hline$O B$ & 0.08 & 0.74 & 0.92 & 0.87 & 1.31 & 1.04 & 0.12 & * & NS \\
\hline $\mathrm{OL}$ & 0.97 & 0.75 & 0.92 & 0.87 & 1.31 & 1.04 & 0.11 & NS & NS \\
\hline
\end{tabular}

BW, body weight; DM, dry matter; SEM, standard error of means; ET, time spent eating; DK, time spent drinking; ST, time spent standing; LY, time spent lying down; SN, time spent sniffing; $\mathrm{OB}$, time spent biting objects; $\mathrm{OL}$, time spent licking objects.

Significance level: ${ }^{* *} p<0.001 ;{ }^{* *} p<0.01 ;{ }^{*} p<0.05$; NS, not significant $(p>0.05)$. 
Table 7. Regression equations of behavioral activities of pigs fed Vachellia tortilis leaf meal

\begin{tabular}{lccc}
\hline Activity & $\mathbf{R}^{2}$ & Equation & $\begin{array}{c}\text { Significance } \\
\text { levels }\end{array}$ \\
\hline ET & 0.16 & ET $=-0.051(0.032) x-2.349(0.048)$ & $* * *$ \\
ST & 0.07 & ST $=0.107(0.103) x+1.152(0.156)$ & $*$ \\
LY & 0.05 & LY $=-0.101(0.058) x+2.58(0.089)$ & $*$ \\
OB & 0.13 & OB $=0.0822(0.113) x+0.67(0.172)$ & $*$ \\
\hline
\end{tabular}

$E T$, time spent eating; $S T$, time spent standing; $L Y$, time spent lying down; $O B$, time spent biting object.

Values in parentheses are standard errors of the estimates.

1) Behavioral activities displayed are only those showed statistical differences. Significance level: ${ }^{* *} p<0.001 ;{ }^{* *} p<0.01 ;{ }^{*} p<0.05$; NS not significant $(p>0.05)$.

7. Number of visits to the feeder decreased linearly $(\mathrm{p}<0.0 .5)$ with increasing levels of $V$. tortilis (Figure 1). There was a quadratic response in average daily feed intake versus inclusion level of $V$. tortilis. The relationship between $V$. tortilis leaf meal against condensed tannins and fiber is shown in Table 8 . The negative linear relationship $(\mathrm{p}<0.05)$ between condensed tannins versus time spent eating, number of feeder visits, lying down was observed. Condensed tannins also exhibited a positive linear relationship $(\mathrm{p}<0.05)$ with time spent standing and biting objects. The NDF caused a linear decrease $(\mathrm{p}<0.05)$ in number of feeder visits, time spent eating, time spent standing. In the meantime, NDF linearly increased $(\mathrm{p}<$ 0.05) time spent biting objects. Time spent standing, lying
Table 8. Relationship between behavioral activities against condensed tannins and fiber on behavioral activities

\begin{tabular}{lccc}
\hline Activity $^{1)}$ & Component & Regression & Significance level \\
\hline ET & CT & Linear decrease & $* * *$ \\
FV & CT & Linear decrease & $*$ \\
ST & CT & Linear increase & $*$ \\
LY & CT & Linear decrease & $*$ \\
OB & CT & Linear increase & $*$ \\
ET & NDF & Linear decrease & $*$ \\
FV & NDF & Linear decrease & $*$ \\
ST & NDF & Linear decrease & $* *$ \\
OB & NDF & Linear increase & $* *$ \\
ST & ADF & Linear decrease & $* *$ \\
LY & ADF & Linear decrease & $*$ \\
OB & ADF & Linear decrease & $*$ \\
\hline
\end{tabular}

$E T$, time spent eating; $C T$, condensed tannins; $F V$, number of feeder visit; $S T$, time spent standing; LY, time spent lying down; OB, time spent biting object; NDF, neutral detergent fiber; $A D F$, acid detergent fiber.

1) Behavioural activities displayed are only those showed statistical difference. Significance level: ${ }^{* *} p<0.001 ;{ }^{* *} p<0.01 ;{ }^{*} p<0.05$; NS, not significant $(p>0.05)$

down and biting objects decreased in a negative linear fashion $(\mathrm{p}<0.05)$ in response to ADF.

\section{DISCUSSION}

To understand welfare aspect and feeding value of $V$. tortilis

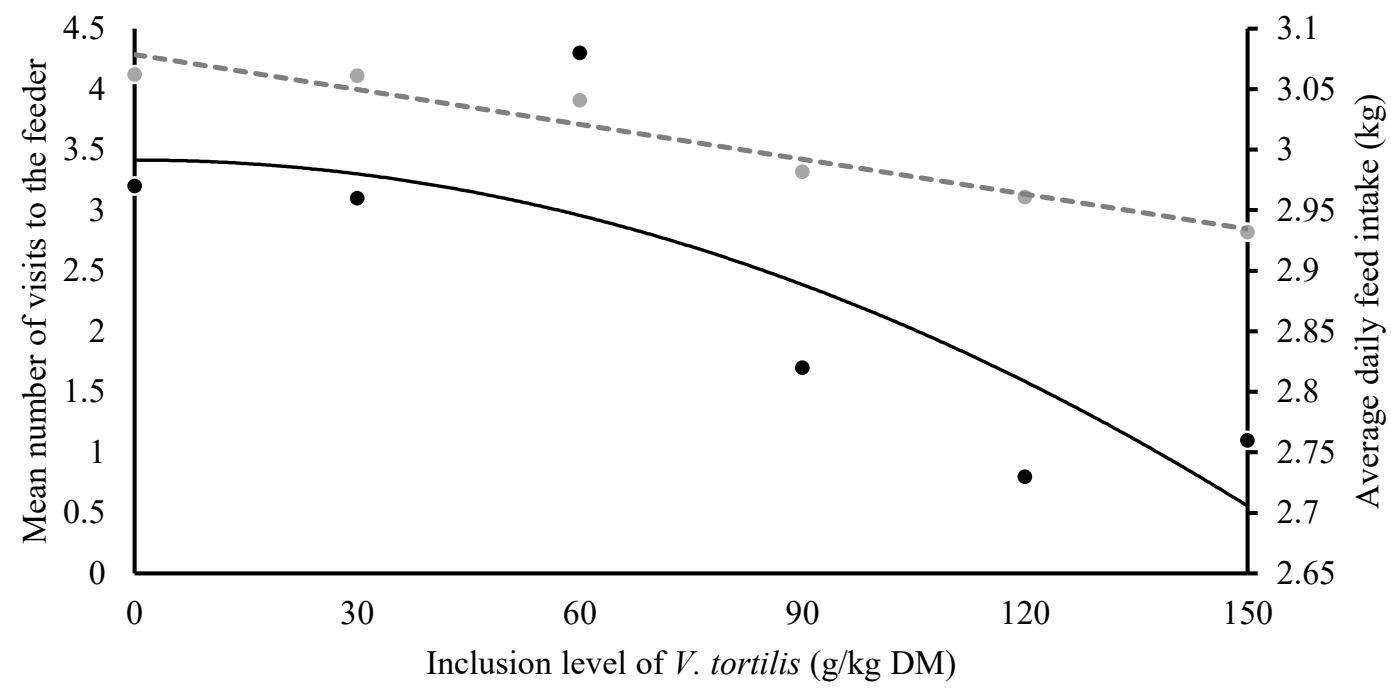

*Average daily feed intake $=-0.02 \mathrm{x}^{2}+2,9914 \mathrm{R}^{2}=0.6547 \mathrm{p}<0.05$

Feeder visits $=-0.0096 \mathrm{x}+4.2857 \mathrm{R}^{2}=0.9407 \mathrm{p}<0.05$

-... (Number of visits to the feeder )

- (Average daily feed intake)

Figure 1. Response in number of visits and average daily gain against inclusion levels of Vachellia tortilis. * Values of average daily feed were adapted from Thabethe et al [4]. 
leaf meal in pigs, it is pertinent to not only conclude by determining feed intake and growth performance $[1,4]$ but also changes in behavioral activities are crucial. To the best of our knowledge, behavioral response of pigs to tanning-containing feedstuff are reported for the first time. Finishing uncastrated male pigs (boars) are important for swine breeding programs and production. Photoperiod has a direct impact on behavioural activities in pigs [18]. Therefore, behavior was not recorded from when artificial light was used $(1800 \mathrm{~h}$ to 0800 h). In addition, majority of pigs in the study were inactive after $1800 \mathrm{~h}$ and started to be active around $0800 \mathrm{~h}$ the next morning when personnel were arriving to provide new feed [6] Hence, recordings during inactive time were not done. A positive correlation (both feeder visits and time spent decreased) between time spent eating and number of visits could be due to inherent property of tannins from $V$. tortilis. Condensed tannins diminish weight gain and reduce feed efficiency by inhibiting protein digestion and releasing astringent taste $[2,19]$. A positive correlation between number of feeder visits and time spent drinking was anticipated. Apart from addressing hydration requirement, drinking is responsive to feeding. A negative correlation between number of visits to the feeder against time spent standing, sniffing walls and licking objects suggest that finishing pigs were exploring non-stereotypic behaviors such as drinking after visiting the feeder. A lack of correlation between time spent eating against other behavioral activities was unanticipated. This may mean that inclusion level of $V$. tortilis resulted to unmeasured behaviors such as time spent mounting walls, rubbing against the walls, sitting and walking around in the pen. These behavioral activities may symbolize uncomfortability of pigs due to reduction in appetite as a result of $V$. tortilis.

There was a negative correlation between ADF against time spent standing, sniffing walls and biting objects. The ADF is ingestible component of the feed, which consists of cellulose and lignin. A temporal fullness of the gut due to distension can be accountable for reduced time spent on behavioral activities such as sniffing walls and biting objects [20]. The NDF contains hemicellulose, lignin and cellulose, of which hemicellulose is partially fermented by gastrointestinal microbiota that produces exogenous enzymes in the gut of pigs [6]. The observed negative correlation between NDF versus time spent eating and number visits to the feeder could be related to hydrophilic polysaccharides, such as hemicellulose, found in $V$. tortilis that can absorb water and hold it in the lumen of the gut [21]. De Leeuw et al [20] reported high absorption, swelling, stomach wall distension in pigs consuming feed with high WHC, which results to satiety and henceforth number of visits to the feeder and time spent eating are reduced. A positive correlation between NDF and time spent standing, sniffing walls and biting objects was mainly due to a decrease in feeder visits and time spent eating.
Proanthocyanidins showed a negative correlation with time spent eating and feeder visits, suggesting that finishing pigs struggled to withstand the deleterious effects of the condensed tannins found in $V$. tortilis. Diets that are rich in condensed tannins give rise to astringent sensation in the mouth, thereby inducing negative feedback, prompting pigs to reduce feed consumption [22]. This sensation also reduces feed palatability and nutrient digestibility [19]. A positive correlation between condensed tannins and time spent standing, sniffing walls, biting and licking objects is entirely explained by a compromise time spent eating and visit to the feeder, which subject pigs into stereotypic behaviors. In contrast, Day et al [23] indicated that decreased in stereotypic behavioral activities is among positive effect of caused by condensed tannins. This largely depends upon the type of leguminous tree used, content of tannins available and its molecular weight.

Surprisingly, a negative linear relationship between time spent eating and levels of $V$. tortilis was observed. As reported on growth performance study [4], a quadratic decrease instead of linear was expected, where pigs would take some time to consume feed containing tannin-rich $V$. tortilis until a certain inclusion level where optimum time spent eating and feeder visits are reduced. A linear decrease suggests that $V$. tortilis inclusion drastically gave rise to astringent taste, a dryness flavor coupled with sour or bitter flavor that is normally produced by condensed tannins in the leaves. This irritable taste deterred pigs from eating feed containing $V$. tortilis, thus reducing the duration eating. Astringent taste is known to reduce feed intake and palatability [1,24].

A suppression of appetite and promotion of feed refusal caused by condensed tannins [2] may be the reason of linear decrease in number feeder visits with increasing levels of $V$. tortilis. In a growth performance study conducted by Thabethe et al [4] on finishing pigs, average daily feed intake showed a quadratic relationship with increasing levels of $V$. tortilis. A linear decrease in number of feeder visits was, therefore difficult explain. It could be due to condensed tannins that subjected finishing pigs to consume more feed containing $V$. tortilis (by virtue of large body capacity) in each visit to the feeder to meet their requirements until the feed intake is supressed. Condensed tannins are widely recognized as anti-nutritional factors to animals [19]. Pigs have a limited ability to utilise tannin-rich feedstuff due to their physiological nature. It is because, unlike ruminants, they do not have bacteria, which counter the effects of tannins [2]. This also explains a linear decrease in feeder visits against condensed tannins. A negative linear relationship between time spent eating and feeder visits against NDF was tricky to explain. This is because it is accepted that an increase in fibrous property (NDF) of $V$. tortilis reduces nutrient density, thus promoting feed intake and time spent eating to meet their nutrient requirement until the gut capacity is reached, then 
feed intake and time spent eating is reduced [6]. The linear decrease in time spent eating against NDF could be due to fact that finishing pigs have a facility to efficiently utilize fiber by virtue of hindgut fermentation.

A linear decrease in time spent lying down with increasing levels of $V$. tortilis may be chiefly related to a decrease in time spent eating and visiting the feeder. Lying down is often the reaction after feeding behavioral activities such as time spent eating and drinking. A decrease in time spent lying down could, therefore, be due to frustration as result of decrease time spent eating and feeder visits. A linear increase in time spent standing and biting objects might be attributed to linear decrease in time spent lying down. Substrate-directed behaviors occur when there is a poor palatability of the feed. However, palatability was not measured in the current study. Linear behavioral responses of finishing pigs found in the present study preclude from estimating optimal inclusion levels of $V$. tortilis.

\section{CONCLUSION}

Inclusion level of $V$. tortilis leaf meal diets alters the behavioral activities of finishing pigs. It reduces time spent eating, lying down and the number of feeder visit while prolonging time spent standing and biting of objects. It is understood that changes in behavioral activities are due to condensed tannins, NDF and ADF. To maximize utilization of $V$. tortilis, determination of the behavioral activities of finishing pigs fed on $V$. tortilis leaf meal treated with polyphenolic-binding agents is essential.

\section{CONFLICT OF INTEREST}

We certify that there is no conflict of interest with any financial organization regarding the material discussed in the manuscript.

\section{ACKNOWLEDGMENTS}

Authors acknowledge the competitive Grant from the University of KwaZulu-Natal for funding the research.

\section{REFERENCES}

1. Khanyile M, Ndou SP, Chimonyo M. Influence of Acacia tortilis leaf meal-based diets on growth performance of pigs. Livest Sci 2014;167:211-8. https://doi.org/10.1016/j.livsci.2014.04.016

2. Hlatini VA, Ncobela CN, Zindove TJ, Chimonyo M. Use of polyethylene glycol to improve the utilisation of leguminous leaf meals in pigs: a review. S Afr J Anim Sci 2018;48:609-20. http://dx.doi.org/10.4314/sajas.v48i4.2

3. Hlatini VA, Khanyile M, Zindove TJ, Chimonyo M. Feed intake and growth performance of growing pigs fed on Acacia tortilis leaf meal treated with polyethylene glycol. Trop Anim Health Prod 2016;48:585-91. https://doi.org/10.1007/s11250016-1002-0

4. Thabethe F, Mkwanazi MV, Khanyile M, Chimonyo M. Adaptation of finishing pigs to graded levels of Vachellia tortilis leaf meal diet. Livest Sc 2018;218:20-5. https://doi. org/10.1016/j.livsci.2018.08.014

5. Meunier-Salaün MC, Edwards SA, Robert S. Effect of dietary fibre on the behaviour and health of the restricted fed sow. Anim Feed Sci Technol 2001;90:53-69. https://doi.org/10.1016/ S0377-8401(01)00196-1

6. Bakare AG, Ndou SP, Madzimure J, Chimonyo M. Predicting time spent on different behavioural activities from physicochemical properties of fibrous diets in finishing pigs. Appl Anim Behav Sci 2015;167:1-8. https://doi.org/10.1016/j. applanim.2015.03.012

7. Mlambo V, Marume U, Gajana CS. Utility of the browser's behavioural and physiological strategies in coping with dietary tannins: Are exogenous tannin-inactivating treatments necessary? S Afr J Anim Sci 2015;45:441-51. http://dx.doi.org/10. 4314/sajas.v45i5.1

8. Huisman J, Tolman GH. Antinutritional factors in the plant proteins of diets for non-ruminants. Rec Adv Anim Nutr 1992; 68:101-10.

9. National Research Council. Nutrient requirements of swine, 11th revised edition. Washington, DC, USA: National Academy Press; 2012.

10.AOAC. Official methods of analysis of the Association of Official Analytical Chemists, 15th edition. Washington DC, USA: AOAC International; 1990.

11.Van Soest PV, Robertson JB, Lewis BA. Methods for dietary fiber, neutral detergent fiber, and nonstarch polysaccharides in relation to animal nutrition. J Dairy Sci 1991;74:3583-97.

12. Whittemore EC, Emmans GC, Kyriazakis I. The problem of predicting food intake during the period of adaptation to a new food: a model. Br J Nutr 2003;89:383-98. https://doi. org/10.1079/BJN2002781

13. Kyriazakis I, Emmans GC. The voluntary feed intake of pigs given feeds based on wheat bran, dried citrus pulp and grass meal, in relation to measurements of feed bulk. Br J Nutr 1995; 73:191-207. https://doi.org/10.1079/BJN19950023

14.Abdou N, Nsahlai IV, Chimonyo M. Effects of groundnut haulms supplementation on millet stover intake, digestibility and growth performance of lambs. Anim Feed Sci Technol 2011;169:176-84. https://doi.org/10.1016/j.anifeedsci.2011. 07.002

15. Reed JD, McDowell RTE, Van Soest PJ, Horvath PRJ. Condensed tannins: a factor limiting the use of cassava forage. J Sci Food Agric 1982;33:213-20. https://doi.org/10.1002/jsfa. 2740330302

16. Mills PA, Rotter RG, Marquardt RR. Modification of the glu- 
cosamine method for the quantification of fungal contamination. Can J Anim Sci 1989;69:1105-6. https://doi.org/10.4141/ cjas89-128

17.SAS. SAS user's guide: Statistics, Version9.1. Cary, NC, USA: SAS Institute; 2009.

18. Reiners K, Hessel EF, Sieling S, Van den Weghe HF. Influence of photoperiod on the behavior and performance of newly weaned pigs with a focus on time spent at the feeder, feed disappearance, and growth. J Swine Health Prod 2010;18: 230-8.

19. Butler LG. Effects of condensed tannin on animal nutrition. In: Chemistry and significance of condensed tannins. Boston, MA, USA: Springer; 1989. pp. 391-402.

20.De Leeuw JA, Bolhuis JE, Bosch G, Gerrits WJJ. Effects of dietary fibre on behaviour and satiety in pigs. In: Symposium on 'Behavioural nutrition and energy balance in the young. Proc Nutr Soc 2008;67:334-42.

21.Ndou SP, Khanyile M, Chimonyo M. Growth performance and nutrition-related serum metabolites in growing pigs fed on Acacia Tortilis leaf meal. Livest Sci 2015;182:22-7. https:// doi.org/10.1016/j.livsci.2015.10.003

22.Frutos P, Hervas G, Giráldez FJ, Mantecón AR. Tannins and ruminant nutrition. Span J Agric Res 2004;2:191-202.

23.Day JEL, Kyriazakis I, Lawrence AB. The use of a second-order schedule to assess the effect of food bulk on the feeding motivation of growing pigs. Anim Sci 1996;63:447-55.

24. Ngwa AT, Nsahlai IV, Bonsi MLK. Feed intake and dietary preferences of sheep and goats offered hay and legume-tree pods in South Africa. Agroforest Syst 2003;57:29-37. https:// doi.org/10.1023/A:1022988200484 